\title{
Retrospective record based study of maternal and fetal outcome in induction of labour at 40 and 41 weeks of gestation in uncomplicated primigravida women
}

\author{
Mamta N. Anand ${ }^{1 *}$, Sunita M. Ubale ${ }^{1}$, Neelesh P. Anand ${ }^{2}$, \\ Priti Naykodi $^{1}$, Jaynarayan B. Senapati ${ }^{1}$, Anjali A. Babalgaonkar ${ }^{1}$
}

\author{
${ }^{1}$ Department of Obstetrics and Gynaecology, Rajiv Gandhi Medical College, Kalwa, Thane, Maharashtra, India \\ ${ }^{2}$ Department of Paediatrics, Rajmata Mata Jijau Hospital, Airoli, Navi Mumbai, Maharashtra, India
}

Received: 19 January 2022

Revised: 09 February 2022

Accepted: 10 February 2022

\section{*Correspondence:}

Dr. Mamta N. Anand,

E-mail: drmamtaneeleshanand@yahoo.co.in

Copyright: (C) the author(s), publisher and licensee Medip Academy. This is an open-access article distributed under the terms of the Creative Commons Attribution Non-Commercial License, which permits unrestricted non-commercial use, distribution, and reproduction in any medium, provided the original work is properly cited.

\begin{abstract}
Background: The objective of the study was to compare maternal and foetal outcome after induction in two groups: women who were induced at 40-weeks and at 41-weeks.

Methods: This was a retrospective study conducted over period of one year from 1 January 2018 to 31 December 2018 in the obstetrics and gynaecology department. A total of 200 uncomplicated primigravida women were included in the study. The data was collected and comparative analysis was done between two groups: control group (group A), women with induction at 40 weeks; study group (group B), women with induction at 41 weeks. The outcome was then analysed in terms of mode of delivery, oligohydramnios, meconium-stained liquor, Apgar score, need of NICU, perinatal death. The data was collected, analysed and statistical analysis was done using the Chi square test.

Results: Out of total 200 women, 104 women were of 40 weeks and 96 women had completed 41 weeks. The LSCS rate was reduced from $25.96 \%$ to $17.7 \%$, when the labour was induced at 41 weeks, the instrumental delivery rate was low in the study group compared to the control group. Even though the meconium staining of liquor was high but NICU admission and perinatal mortality was comparatively lower in the study group.

Conclusions: Induction of labour done at 41 weeks is associated with reduced maternal morbidity and no adverse effect on the perinatal outcome as compare to induction at 40 weeks.
\end{abstract}

Keywords: Induction of labour, Mode of delivery, Perinatal outcome

\section{INTRODUCTION}

Induction of labour is one of the most common procedures during pregnancy. Data from the National centre for health statistics for the last decade indicate that the rate of labour induction has increased gradually from $9 \%$ to $20 \%$.

Indications for induction of labour have essentially not changed. When concern for the wellbeing of the mother arises, primary indications for induction include active medical disorders, being well beyond the due date and prolonged ruptured membranes. Indication is also justified when the foetus is at risk. Another general concept is the recognition that induction is associated with increased complications as compared with spontaneous labour. Complications include an increase of chorioamnionitis and increased caesarean delivery.

Increase in caesarean delivery rates associated with induction can be due to the uterus being poorly prepared 
for labour and the physician's preferences regarding the duration of attempt at induction, especially in circumstances of the unripe cervix. The American college of obstetricians and gynaecologists practice bulletin induction of labour states, generally induction of labour has merit as a therapeutic option when the benefits of expeditious delivery outweigh the risks of continuing pregnancy. The benefit of labour induction must be weighed against the potential maternal or foetal risks associated with the procedure.

It has been shown that maternal complications of pregnancy could increase after 40 weeks gestation in lowrisk women, especially primigravida. ${ }^{2}$ In low-risk pregnancy at term, it has been suggested that active management of risk through the use of preventive labour induction prior to possible development of uteroplacental insufficiency or cephalo-pelvic disproportion can improve birth outcomes and reduce caesarean section rates. ${ }^{3,4}$ Since women in Asia and Africa have been shown to have a shorter duration of pregnancy compared with European women the authors of this appraisal recommend that clinicians in those regions should regard recommendation no. 1 (IOL for women known with certainty to have reached 41 weeks of gestation) as strong. ${ }^{5-7}$

Maternal risks included emergency caesarean delivery, vacuum extraction or forceps delivery, cephalopelvic disproportion, cervical rupture, perineal lacerations, dystocia, large foetus, foetal death, postpartum haemorrhage. Neonatal risks were asphyxia, aspiration, admission to intensive care after birth, bone fracture, peripheral nerve paralysis and others. ${ }^{8-10}$ In underresourced settings where ultrasound scanning facilities were not available to date pregnancies accurately, there would be a need to educate and motivate pregnant women to attend prenatal clinics early to allow clinical dating of the pregnancy. On the other hand, there was no rationale for IOL. Further evidence was required regarding benefits and undesirable effects of IOL between 40 and 41 weeks. ${ }^{3,4}$

A policy of labour induction after 40 completed weeks or later, compared to awaiting spontaneous labour for at least one week (41 weeks) was associated with fewer perinatal deaths and meconium aspiration syndrome, without an increased risk of caesarean section $(\mathrm{A}) .{ }^{11}$ Centres varied in the availability of tests for foetal surveillance and the ability to cope with the demand. Based on these factors, it was difficult to have a uniform policy for management of post term pregnancy. Considering the above literature, we have done a study to compare the effect of induction of labour at 40 weeks and 41 weeks. Objective of the study was to compare maternal and foetal outcome after induction in two groups: women who induced at 40-week group (40+0 to $40+6$ days) and women who induced at 41 week group ( $41+0$ to $41+6$ days).

Herein this study we compared the pregnancy outcome of those intervened at forty weeks of gestation and those at forty-one weeks and thereby arriving at an optimum period for intervention in these pregnancies.

As many people in India lived in villages, with inadequate approach to health care facilities and also due to illiteracy, many women come to our hospital beyond 40 to 41 weeks of gestation. Such patients were included in one group for the purpose of study.

The problems associated with pregnancy that crossed expected days of delivery were 1.1: mother became anxious and feared any danger for the foetus; mother was at increased risk of operative delivery; foetus was at increased risk for post maturity, foetal distress, meconiumstained amniotic fluid, meconium aspiration syndrome, foetal heart rate abnormalities.

The objective of study was to study the maternal and foetal outcome of the uncomplicated primigravida women induced at 40th week and 41 st week of gestation.

\section{METHODS}

The present study was a retrospective record-based study which was carried out in the obstetrics and gynaecology department, in Rajiv Gandhi medical college during the period from 1 January 2018 to 31 December 2018. A total of 200 uncomplicated primigravida women fulfilling the inclusion and exclusion criteria were included in the study.

The data was collected and comparative analysis was done in as following:

\section{Control group (group A)}

Uncomplicated primigravida women with 40 weeks of gestation for whom induction of labour was done.

\section{Study group (group B)}

Uncomplicated primigravida women with 41 weeks of gestation for whom induction of labour was done.

\section{Inclusion criteria}

Full term primigravida at 40 and 41 weeks, age group 1845 years, pregnancies with reliable dates, previous regular menstrual cycles, gestational dating was confirmed by ultrasonography performed between 12-22 weeks of pregnancy were included in the study.

\section{Exclusion criteria}

Multigravida maternal age groups 44 years, unknown dates, irregular menstrual cycles, anomalous foetus, malpresentation, maternal complications like cephalopelvic disproportionate, pre-eclampsia, diabetes and cardiac diseases in pregnancy, women who reported in spontaneous labour were excluded. 


\section{Methodology}

Ethical clearance was obtained from institutional ethics committee of Rajiv Gandhi medical college, Kalwa, Thane. Data was collected based on the inclusion criteria. Total 200 patients were included in study. The following outcome measures were analysed in both the groups: amount of AFI, incidence of meconium-stained liquor, mode of delivery, birth weight, Apgar score at birth, need for NICU admission, perinatal death.

\section{Statistical analysis}

The data collected in the study was entered in the computer using Microsoft excel 2013. Qualitative data was presented in the form of frequency and percentages.

The data was collected, analysed and comparison was done between the two groups. Statistical analyses were performed using statistical programs SPSS for Windows (version 20.1). All variables were analysed using the chisquare test. The $\mathrm{p}$ value less than 0.05 was considered as statistically significant.

\section{RESULTS}

Total number of women completed 40 weeks of gestation were $104(52 \%)$ and those >41 weeks were 96 (48\%) (Table 1).

Table 2 shows that there is no statistically significance in the amniotic fluid index in both study group and control group $(\mathrm{p}>0.05)$.
Table 1: Distribution of women according to the gestational age.

\begin{tabular}{|ll|}
\hline $\begin{array}{l}\text { Distribution } \\
\text { Control group (women with } \mathbf{2 4 0}\end{array}$ & Total \\
weeks of gestation) & 104 \\
\hline $\begin{array}{l}\text { Study group (women with } \mathbf{2 4 1} \\
\text { weeks of gestation) }\end{array}$ & 96 \\
\hline Total & 200 \\
\hline
\end{tabular}

Table 2: Association of amniotic fluid index in control and study group.

\begin{tabular}{|lll|}
\hline AFI & Control group & Study group \\
\hline$<\mathbf{5}$ & 2 & 1 \\
\hline $\mathbf{5 - 8}$ & 12 & 13 \\
\hline $\mathbf{8 - 1 0}$ & 65 & 52 \\
\hline$>\mathbf{1 0}$ & 24 & 29 \\
\hline Polyhydramnios & 1 & 1 \\
\hline Total & 104 & 96 \\
\hline
\end{tabular}

$\mathrm{P}=0.6, \mathrm{p}>0.05$, statistically not significant.

In the present study, $15.5 \%$ patients developed meconiumstained liquor in control group as compare to $20 \%$ patients in study group, but the difference was not significant (Table 3).

In the present study, the incidence of LSCS was $25 \%$ in control group and $17.7 \%$ in study group but the difference is statistically not significant (Table 4).

Table 3: Association of meconium-stained amniotic fluid in control and study group.

\begin{tabular}{|llllll|}
\hline Weeks & Grade-I & Grade-II & Grade-III & Total & $\%$ \\
\hline Control group & 9 & 3 & 4 & 16 & 15.5 \\
\hline Study group & 10 & 2 & 7 & 19 & 20 \\
\hline
\end{tabular}

Student t test, $\mathrm{p}>0.05$, not significant.

Table 4: Association of incidence of LSCS and vaginal delivery in study and control group.

\begin{tabular}{|ll|ll|}
\hline \multirow{2}{*}{ Groups } & LSCS & Vaginal delivery & Total \\
\cline { 2 - 4 } & $\mathbf{N}(\mathbf{\%})$ & $\mathbf{N}(\mathbf{\%})$ & 104 \\
\hline Control group (A) & $27(25)$ & $77(75)$ & 96 \\
\hline Study group (B) & $17(17.7)$ & $79(84)$ & 200 \\
\hline Total & 44 & 156 & \\
\hline
\end{tabular}

$P$ value is $1.96, p>0.05$, not significant.

Table 5: To compare the statistical significance of instrumental delivery in A and B.

\begin{tabular}{|c|c|c|c|}
\hline \multirow{2}{*}{ Groups } & Instrumental delivery & Vaginal delivery & \multirow{2}{*}{ Total } \\
\hline & $\mathbf{N}(\%)$ & $\mathbf{N}(\%)$ & \\
\hline Control group (A) & $18(23)$ & $59(77)$ & 77 \\
\hline Study group (B) & $7(8.8)$ & $72(91.1)$ & 79 \\
\hline Total & 25 & 131 & 156 \\
\hline
\end{tabular}

By Chi square test $\mathrm{p}<0.05$ value significant. 
Table 6: To compare the statistical significance of perinatal death in study and control group.

\begin{tabular}{|c|c|c|c|}
\hline \multirow{2}{*}{ Groups } & Perinatal death & Baby Alive & \multirow{2}{*}{ Total } \\
\hline & $\mathbf{N}(\%)$ & $\mathbf{N}(\%)$ & \\
\hline Control group (A) & $3(2.8)$ & $101(97.1)$ & 104 \\
\hline Study group (B) & $2(2.08)$ & $94(97.9)$ & 96 \\
\hline Total & 5 & 195 & 200 \\
\hline
\end{tabular}

$\mathrm{P}=0.42, \mathrm{p}>0.05$, not significant.

Table 7: Association of birth weight in control and study group.

\begin{tabular}{|lll|}
\hline Birth weight (kgs) & Control group & Study group \\
\hline$<\mathbf{2}$ & 2 & 3 \\
\hline $\mathbf{2 - 2 . 5}$ & 26 & 21 \\
\hline $\mathbf{2 . 5}-\mathbf{3 . 5}$ & 75 & 70 \\
\hline$>\mathbf{3 . 5}$ & 1 & 2 \\
\hline
\end{tabular}

By Chi square test $\mathrm{p}$ value $>0.05$.

Table 8: Association of perinatal outcome in study and control group.

\begin{tabular}{|c|c|c|c|}
\hline \multirow{2}{*}{ Outcome } & Control group & Study group & \multirow{2}{*}{ P value } \\
\hline & $\mathrm{N}(\%)$ & $\mathrm{N}(\%)$ & \\
\hline NICU admission & $12(11.53)$ & $8(8.3)$ & $<0.05$ \\
\hline Apgar score <7 & $3(2.8)$ & $7(7.2)$ & $<0.05$ \\
\hline
\end{tabular}

By Chi square test $\mathrm{p}$ value less than 0.05 .

The incidence of vaginal delivery was $75 \%$ in control group as compared to $84 \%$ in study group, but the difference is not significant.

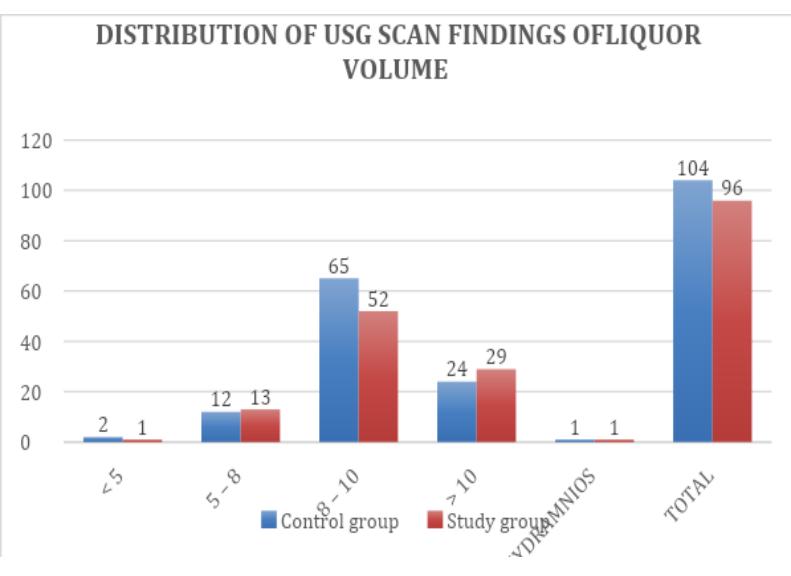

Figure 1: Distribution of USG scan findings of liquor volume.

The incidence of instrumental delivery when induction of labour done in control group was $23 \%$ which significantly differed from the study group which was $8.8 \%$ (Table 5).

Hence perinatal outcome in the form of mortality was $2.8 \%$ in control group as compared to $2.08 \%$ in study group but the difference was not statistically significant (Table 6).

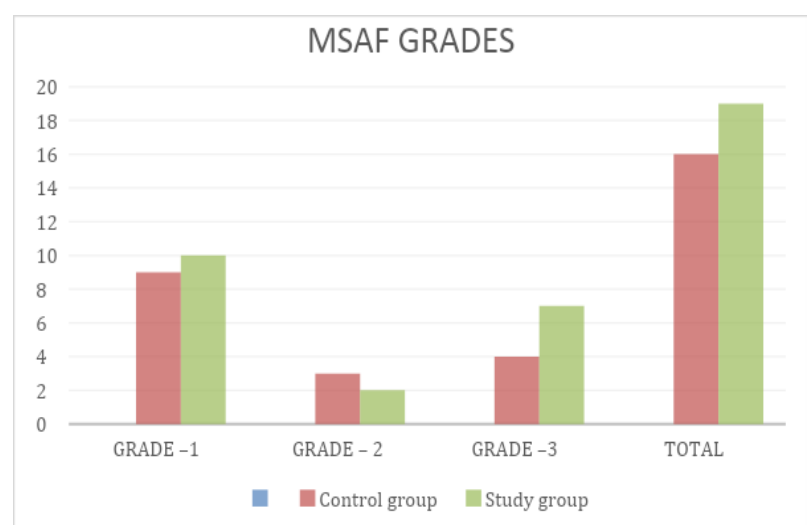

Figure 2: MSAF grades.

In the present study there was no statistically significant difference in the birth weight in control and study group (Table 7).

In present study, the need of NICU admission in control group was $11.53 \%$ as compared to $8.3 \%$ in study group, but the difference was not significant (Table 8).

The Apgar score $<7$ was seen in $2.8 \%$ patients in control group as compared to $7.2 \%$ in study group, but the difference was statistically not significant.

\section{DISCUSSION}

The study population consisted of 200 women who had gone beyond the expected date of confinement. Total 
number of women completed 40 weeks of gestation were $104(52 \%)$ and those $>41$ weeks were $96(48 \%)$.

In the present study the incidence of oligohydramnios (AFI $>8 \mathrm{~cm}$ ) was $13.4 \%$ in control group as compared to $14.5 \%$ in study group.

In the present study, the incidence of meconium-stained liquor was $15.5 \%$ as compared to $20 \%$ in study group. The similar result was seen in Williams obstetrics where $21 \%$ of patients developed meconium-stained liquor at 40 weeks as compared to $25 \%$ at $41 .{ }^{35}$ Similar results were seen in Steer et al and Miller et al 1981..$^{33,34}$

In the present study, the incidence of LSCS was $25 \%$ in control group and $17.7 \%$ in study group but the difference was statistically not significant. Induction of labour after 41 weeks did not increase caesarean section rate. ${ }^{15}$ This result was the same as that of review of meta-analysis of 12 trials involving 6,284 women, Henry et al, Katz et al, Suikkari et al, Augensen et al, Dyson et al, Bergsjo et al, Martin et al, Hannah et al, Herabutya et al and Rogers et al. ${ }^{21-23,25,27-30,34,36,38}$ Perinatal outcome was not statistically significant from those induced at 41 weeks.

In the present study there was no statistically significant difference in the birth weight in control and study group. The incidence of macrosomia was $0.96 \%$ in control group and $2.3 \%$ in study group. The similar result was seen in Elden et al where the macrosomia was seen in $0.8 \%$ at 40 weeks and $2.8 \%$ at 41 weeks. $^{12}$

In present study, the need of NICU admission in control group was $11.53 \%$ as compared to $8.3 \%$ in study group. Similar result was seen in Sanchez-Ramos et al where the NICU admission was $11.7 \%$ at 40 weeks as compared to $12.5 \%$ at 41 weeks. ${ }^{39}$

The Apgar score $<7$ was seen in $2.8 \%$ patients in control group as compared to $7.2 \%$ in study group. The result was comparable with Sanchez-Ramos et al where $1.1 \%$ showed Apgar $<7$ at 40 weeks and $1.4 \%$ at 41 weeks. $^{39}$

In our study, perinatal outcome in the form of mortality was $2.8 \%$ in control group as compared to $2.08 \%$ in study group but the difference was not statistically significant.

Indian studies quoted perinatal mortality in 40 weeks and above as $14 \%$ and no difference in perinatal mortality at 40 and 41 weeks. ${ }^{32}$ In our study also there was no statistical difference in PNMR between 40 weeks and 41 completed weeks.

Two randomised trials compared a policy of routine induction at 40 weeks Cole et al and Bergsjo et al against expectant management till 42 weeks gestation. ${ }^{14,15}$ These trials revealed no evidence of any major benefit or risk to routine induction at 40 weeks. There was no effect on the caesarean section. But obviously, induction around 40 weeks reduced the incidence of meconium staining in the labour.

\section{Limitation}

The limitation of the present study was that the method of induction of labour used was not uniform for all patients in study and control groups.

\section{CONCLUSION}

Whenever a pregnant woman crosses her date of confinement, the patient becomes anxious and the obstetrician keeps the finger crossed. If the patient doesn't go into spontaneous labour, induction of labour becomes very important line of management in all post-dated pregnancies. After reaching the expected date of delivery how long to wait is question of debate. From the study conducted, we get the inference that the caesarean section rate is reduced from $25.96 \%$ to $17.7 \%$, when the labour is induced at 41 weeks, one week beyond the expected date of confinement. Also, the instrumental delivery rate is low $(7.3 \%)$ in the study group compared to the control group $(17.26 \%)$. From the study we concluded that when the induction of labour is done at 41 weeks the chances of LSCS is reduced as compared to induction done at 40 weeks. Hence with close monitoring of progress of labour by maintaining partogram, foetal heart rate monitoring and if the liquor is clear, induction done at 41 weeks had more chances of delivering vaginally hence reducing the maternal morbidity and prolonged hospital stay. Even though the meconium staining of liquor is high in the study group (20\% versus $15.5 \%)$, NICU admission and perinatal mortality is comparatively lower in the study group. From our study we concluded by we can safely wait with watchful expectancy till 41 weeks of gestation in all uncomplicated primigravida patients. So, the induction of labour in otherwise uncomplicated pregnancies, at 41 weeks is associated with reduced maternal morbidity and no adverse effect on the perinatal outcome.

Funding: No funding sources

Conflict of interest: None declared

Ethical approval: The study was approved by the Institutional Ethics Committee

\section{REFERENCES}

1. American College of Obstetricians and Gynecologists. Management of postterm pregnancy: ACOG technical bulletin no. 55. Obstet Gynecol. 2004;103(3):639-45.

2. Caughey AB, Bishop JT. Maternal complications of pregnancy increase beyond 40 weeks of gestation in low-risk women. J Perinatol. 2006;26(9):540-5.

3. Nicholson JM, Caughey AB, Stenson MH, Cronholm PF, Kellar LC, Bennet I. The active management of risk in multiparous pregnancy at term: association between a higher prevention labor induction rate and 
improved birth outcomes. Am J Obstetr Gynaecol. 2009;200(3):1-250.

4. Nicholson MD, Kellar LC, Cronholm PF, Macones GA. Active management of risk in pregnancy at term in an urban population: an association between a higher induction of labor rate and a lower Caesarean delivery rate. Am J Obstetr Gynaecol. 2004;191(5):1516-28.

5. Patel RR, Steer P, Doyle P, Little MP, Elliot P. Does gestation vary by ethnic group? A London-based study of over 122,000 pregnancies with spontaneous onset of labour. Int J Epidemiol. 2004;32(1):107-13.

6. Mathai M, Thomas S, Peedicayil A, Regi A, Jasper P, Joseph R. Growth pattern of the Indian fetus. Int J Gynaecol Obstetr. 1995;48(1):21-4.

7. Goonewardene M, Rameez MFM, Kaluarachchi A, Perera $\mathrm{H}$. WHO recommendations for induction of labour: RHL commentary. The WHO Reproductive Health Library; Geneva: World Health Organization. Available at: http://apps.who.int/rhl/pregnancy_ childbirth/induction/guidelines_goonewardeneme_co m/en/index.html. Accessed on 20 November 2011.

8. Briscoe D, Nguyen H, Mencer M, Gautam N, Kalb DB. Management of pregnancy beyond 40 weeks gestation. Am Fam Physician. 2005;71(10):1935-41.

9. Olesen AW, Westergaard JG, Olsen J. Perinatal and maternal complications related to post term delivery: a national register-based study, 1978-1993. Am J Obstet Gynecol. 2003;189(1):222-7.

10. Heimstad R, Romundstad PR, Hyett J, Mattsson LA, Salvesen KA. Women's experiences and attitudes towards expectant management and induction of labor for post-term pregnancy. Acta Obstetricia Gynecologica Scandinavica. 2007;86(8):950-6.

11. Resnik R, Calder A. Post term pregnancy. In: Creasy RK, Resnik R. Maternal fetal medicine. 4th ed. Philadelphia: W. B. Saunders; 1999: 532-7.

12. Elden H, Hagberg H, Wessberg A, Sengpiel V, Herbst A, Bullarbo M, et al. Study protocol of SWEPIS a Swedish multicentre register based randomised controlled trial to compare induction of labour 41 completed gestational weeks versus expected management and induction at 42 completed gesational weeks. BMC Pregnancy Childbirth. 2016;16:49.

13. Kaplan B, Goldman GA, Peled Y, Hecht-Resnick R, Neri A, Ovadia J. The outcome of post-term pregnancy. A comparative study. J Perinat Med. 1995;23(3):183-9.

14. Cole RA, Howie PW, MacNaughton MC. Elective induction of labour. A randomised prospective trial. Lancet. 1975;1(7910):767-70.

15. Breart G, Goujard J, Maillard F, Chavigny C, Rumeau-Rouquette C, Sureau C. Comparison of two obstetrical policies with regard to artificial induction of labour at term. A randomised trial. J Gynecologie Obstetrique Biologie Reproduct. 1982;11:107-12.

16. Alexander JM, McIntire DD, Leveno KJ. Forty weeks and beyond: pregnancy outcomes by week of gestation. Obstet Gynecol. 2000;96(2):291-4.
17. James DK, Steer PJ, Weiver CP, Gonil B. High risk pregnancy. 2nd ed. Mayo Clinic; 2012: 1079-80.

18. Arias FL. Predictability of complications associated with prolongation of pregnancy. Obstet Gynecol. 1987;70(1):101-6.

19. Egarter CH, Kofler E, Fitz R, Husslein P. Is induction of labour indicated in prolonged pregnancy? Results of a prospective randomised trial. Gynecol Obstetr Investigat. 1989;27(4):6-9.

20. Beazley JM, Weekes ARL. Neonatal hyperbilirubinemia following the use of prostaglandin E2 in labour. Br J Obstetr Gynaecol. 1976;83(1):62-7.

21. Yemini KM, Lancet M, Mogilner BM, Ben-Hur H, Caspi B. Non-aggressive management of post-date pregnancies, Eur J obstet Gynecol Reprod Biol. 1983;15(2):71-9.

22. Bergsjo P, Huang GD, Yu SQ, Gao Z, Bakketeig LS. Comparison of induced vs non-induced labor in postterm pregnancy. Acta Obstetricia Gynecologica Scandinavica. 1989;68(8):683-7.

23. Herabutya Y, Prasertsawat PO, Tongyai T, Isarangura $\mathrm{N}$, Ayudthya N. Prolonged pregnancy: the management dilemma. Int $\mathbf{J}$ Gynecol Obstetr. 1992;37(4):253-8.

24. Roach VJ, Rogers MS. Pregnancy outcome beyond 41 weeks gestation. Int $\mathrm{J}$ Gynecol Obstetr. 1997;59(1):19-24.

25. Augensen K, Bergsjo P, Eikeland T, Ashvik K, Carlsen J. Randomized comparison of early versus late induction of labour in post-term pregnancy. BMJ. 1987;294(6581):1192-5.

26. Chanrachkul B, Herabutya Y. Postterm with favorable cervix: is induction necessary? Eur J Obstetr Gynecol Reproduct Biol. 2003;106(2):154-7.

27. Dyson DC, Miller PD, Armstrong MA. Management of prolonged pregnancy: induction of labor versus antepartum fetal testing. Am J Obstet Gynecol. 1987;156(4):928-34.

28. Witter FR, Weitz CM. A randomised trial of induction at 42 weeks of gestation vs expectant management for postdates pregnancies. Am J Perinatol. 1987;4(3):206-11

29. Martin JN, Sessums JK, Howard P, Martin RW, Morrison JC. Alternative approaches to the management of gravidas with prolonged post-term postdate pregnancies. J Mississippi State Assoc. 1989;30(4):105-11.

30. The National Institute of Child Health and Human Development Network of Maternal-Fetal Medicine Units. A clinical trial of induction of labor versus expectant management in postterm pregnancy. Am J Obstet Gynecol. 1994;170(3):716-23.

31. Hannah ME, Hannah WJ, Hellmann J, Hewson S, Milner R, Willan A. Induction of labor as compared with serial antenatal monitoring in post-term pregnancy. N Engl J Med. 1992;326(24):1587-92.

32. Singhal P. Fetomaternal outcome following postdate pregnancy. A prospective study. J Obstet Gynecol India. 2001;51:89-93. 
33. Steer PJ, Eigbe F, Lissauer TJ, Beard RW. Interrelationships among abnormal cardiotocograms in labor, meconium staining of the amniotic fluid, arterial cord blood $\mathrm{pH}$, and Apgar score. Obstet Gynecol. 1989;74(5):715-20.

34. Miller FC, Read JA. Intrapartum assessment of the postdate fetus. Am J Obstet Gynecol. 1981;141(5):516-20.

35. Cunningham FG, Gant NF, Leveno KJ, Gilstrap LC, Hauth JC, Wenstrom KD. Williams Obstetrics. 21st ed. New York, NY: McGraw-Hill; 2001: 738-40.

36. Henry GR. A controlled trial of surgical induction of labour and amnioscopy in the management of prolonged pregnancy. J Obstetr Gynaecol $\mathrm{Br}$ Commonw. 1969;76(9):795-8.

37. Mahapatro A. Fetomaternal outcome in pregnancy beyond 40 weeks. Int J Pharm Bio Sci. 2015;6(2):538.

38. Suikkari AM, Jalkanen M, Heiskala H, Koskela O. Prolonged pregnancy: induction or observation. Acta
Obstetricia et Gynecologica Scandinavica Supplement. 1983;116(4):58.

39. Sanchez-Ramos L, Olivier F, Delke I, Kaunitz AM. Labor induction versus expectant management for postterm pregnancies: a systematic review with metaanalysis. Obstet Gynecol. 2003;101(6):1312-8.

40. Hilder L, Costeloe K, Thilaganathan B. Prolonged pregnancy: Evaluating gestation-specific risks of fetal and infant mortality. $\mathrm{Br} \mathrm{J}$ Obstet Gynaecol. 1998;105(2):169-73.

Cite this article as: Anand MN, Ubale SM, Anand NP, Naykodi P, Senapati JB, Babalgaonkar AA. Retrospective record based study of maternal and fetal outcome in induction of labour at 40 and 41 weeks of gestation in uncomplicated primigravida women. Int J Reprod Contracept Obstet Gynecol 2022;11:739-45. 